\title{
The oral immunogenicity of BioProtein, a bacterial single-cell protein, is affected by its particulate nature
}

\author{
Hanne R. Christensen*, Linea C. Larsen and Hanne Frøkiær \\ BioCentrum-DTU, Section for Biochemistry and Nutrition, Technical University of Denmark, DK-2800 Lyngby, \\ Denmark
}

(Received 17 July 2002 - Revised 3 February 2003 - Accepted 11 February 2003)

\begin{abstract}
The bacterial single-cell protein BioProtein (BP; Norferm Danmark, Odense, Denmark), produced by fermentation of natural gas with methanotrophic bacteria, is a potential protein source for man and animals. For human consumption, removal of the nucleic acid is necessary. Preliminary studies have shown that ingested BP induces a specific immune response. The objective of the present study was to characterize the type of response, its development over time and product-related causative factors. Mice were fed with diets containing $60 \mathrm{~g}$ nucleic acid-reduced BP/kg, $240 \mathrm{~g}$ nucleic acid-reduced BP/kg, $240 \mathrm{~g}$ untreated BP (basic BP) $/ \mathrm{kg}$ or $240 \mathrm{~g}$ casein/kg (control). In another study, mice were fed $240 \mathrm{~g}$ basic BP/kg, whole cell-free BP-culture homogenate or control diet. The immune response was monitored using an ELISA for BP-specific immunoglobulin in blood and BP-specific immunoglobulin A in blood and saliva. Ingested BP induced a steady specific mucosal and systemic immune response, characterized by a dose-dependent production of immunoglobulin and immunoglobulin A in blood and immunoglobulin A in saliva. Basic BP and nucleic acid-reduced BP induced identical responses. However, feeding mice BP-culture homogenate induced immunoglobulin A in saliva but there was no systemic response. The antibodies from BP-fed mice cross-reacted with BP-culture homogenate revealing the presence of the same antigenic components in the two products despite the different oral immunogenicity. Thus, ingestion of BP induces a persistent mucosal and systemic immune response of which the systemic response can be avoided by ingesting a BP preparation free of whole cells. This indicates the importance of the non-particulate constitution of single-cell protein products intended for human or animal consumption.
\end{abstract}

Single-cell protein: BioProtein: Oral immunogenicity: Particulate food antigen

Single-cell protein (SCP) is considered as a potential nonconventional protein source for human food and animal feed to help food-supply problems worldwide in an inexpensive manner. SCP is protein extracted from microbial biomass derived from fermentation of algae, fungi or bacteria, typically by using waste materials as substrate. BioProtein (BP) is a SCP developed by the company Norferm Danmark (Odense, Denmark) and was approved by European Union for use in animal and fish feed in 1995. BP is spray-dried biomass of a mixed methanotrophic bacterial culture grown on natural gas.

Compared with algae and fungi, bacteria have the advantages of rapid growth rate and high protein content of good quality (Kuhad et al. 1997; Anupama \& Ravindra, 2000), but disadvantage of a high content of nucleic acids, up to $160 \mathrm{~g} / \mathrm{kg}$ dry weight. Due to the health complications caused by accumulation of uric acid in the body, this has hampered the use of bacteria as a source of SCP on a commercial basis for human consumption (Anupama \& Ravindra, 2000). Consequently, for the purpose of investigating the potential of $\mathrm{BP}$ for human consumption, Norferm Danmark has, in addition to the basic BP product, developed a nucleic acid-reduced BP product using a heatshock method (Larsen \& Joergensen, 1996).

Even though micro-organisms have played a role in the human diet since ancient times, their utilization has been restricted to micro-organisms naturally occurring in the environment used as fermenting agents, and thus only forming a minor part of the final product. In the case of SCP such as BP, the product consists solely of a microbial material that, although never reported to be pathogenic (Whittenbury $\&$ Krieg, 1984), is of an origin with no history of dietary use. Therefore, besides proper evaluation of nutritive value, there is a requirement to evaluate the safety aspects of SCP products thoroughly. Accordingly, a sub-chronic toxicity study of rats was recently completed by Mølck et al. (2002) to address safety aspects of nucleic acid-reduced BP: the study showed that feeding nucleic acid-reduced BP to rats for 13 weeks activated the immune system, seen as changes in cells from the gut-associated immune system and induction of a systemic antibody response towards the nucleic acid-reduced BP.

The context in which a specific antigen is exposed to the gut mucosa has been shown to have a profound influence 
on the immune response generated towards the antigen, and may in some instances endow the antigen with signals that stimulate a productive response. Unlike a pure soluble antigen, a replicating or particulate antigen, as well as the presence of immune stimulating adjuvant components, are factors of great importance in rendering an otherwise tolerogenic antigen immunogenic (O'Hagan et al. 1989; Strobel \& Mowat 1998). SCP such BP differs from common food protein sources of animal or vegetable origin in some important aspects in relation to the factors mentioned earlier. Consisting solely of microbial material, $\mathrm{BP}$ has indeed a particulate constitution and contains microbial adjuvant components such as endotoxins that are potentially capable of stimulating the immune response.

In view of the critical importance of the nature of a food protein for the resulting immune response upon ingestion, the objective of the present study was to characterize the immune response known to develop toward ingested nucleic acid-reduced BP and to identify product-related causative factors. For this purpose, mice-feeding studies using various doses, feeding times and different preparations of $\mathrm{BP}$ including nucleic acid-reduced $\mathrm{BP}$, basic BP and a whole-cell-free preparation, were carried out. The results showed that ingestion of BP as a whole-cellfree preparation avoided the persistent systemic antibody response otherwise generated towards basic BP, indicating that the physical preparation of SCP products, such as BP intended for human or animal consumption, is indeed an important factor beyond the components per se for the immune response induced upon ingestion.

\section{Materials and methods}

\section{Test materials}

The BP products were provided by Norferm Danmark. $\mathrm{BP}$ is a mixed culture product consisting of approximately $90 \%$ Methylococcus capsulatus (Bath), 6-8\% Alcaligenes acidovorans, $1 \%$ Bacillus brevis DB4 and $1 \%$ Bacillus firmus DB5. Basic BP is a spray-dried granulated culture material containing approximately $(\mathrm{g} / \mathrm{kg})$ : protein (Kjeldahl analysis) 660, fat 90, ash 70 , crude fibre 10 , $\mathrm{N}$-free extract (mainly carbohydrate) 110, water 60 . Nucleic acid-reduced BP is BP culture material further processed to reduce nucleic acids by a heat-shock method that activates endogenous nucleases. For optimal stimulation of the nucleases, Fe is added in this step. Basic BP contains 100-110 g RNA-DNA/kg whereas nucleic acid-reduced BP contains only $20-30 \mathrm{~g} / \mathrm{kg}$.

A BP-culture homogenate free of whole cells was prepared especially for experimental use by homogenizing the bacterial culture suspension (Rannie homogenizer, $100 \mathrm{MPa}$; APV, Albertslund, Denmark) and subsequently ultracentrifuging at $14000 \mathrm{~g}$ for $20 \mathrm{~min}$ at $4^{\circ} \mathrm{C}$ (Varifuge 20RS with a HCT15.1500 continuous flow rotor, 1.5 1; Heraeus Instr., Hanan, Germany) to remove remaining whole cells. The resultant supernatant fraction was stored at $-20^{\circ} \mathrm{C}$ until use. The protein content in the BP-culture homogenate was determined to be $350 \mathrm{mg} / \mathrm{ml}$ by amino acid analysis based on ion-exchange chromatography of a $\mathrm{HCl}$ hydrolysate using $o$-phthalaldehyde post-column derivatization for detection, as described by Barkholt \& Jensen (1989).

For immunization and use in assays for BP-specific antibody and cell reactions, an extract of BP was prepared by shaking $500 \mathrm{mg}$ finely ground BP with $25 \mathrm{ml}$ carbonate buffer $(0.05 \mathrm{M}, \mathrm{pH} 9.6)$ for $30 \mathrm{~min}$, centrifuging for $10 \mathrm{~min}$ at $3000 \mathrm{~g}$ and collecting the supernatant fraction. The pellet was then resuspended in another $25 \mathrm{ml}$ carbonate buffer and incubated overnight at $4^{\circ} \mathrm{C}$ while stirring. After another centrifugation, the resultant supernatant fraction was pooled with the supernatant fraction obtained from the first extraction step. The extract was divided into portions to avoid freeze-thaw cycles and stored at $-20^{\circ} \mathrm{C}$ until use. The protein content in the final BP extract was determined by amino acid analysis as described earlier.

\section{Animals and housing}

Female BALB/c A mice, aged 8-10 weeks, were purchased from M\&B (Ry, Denmark) and acclimatized for 1 week before use in experiments. Mice were held four to six per cage at $20-22^{\circ} \mathrm{C}$ with a $12 \mathrm{~h}$ light-dark cycle in a negative-pressure ventilated area. They were housed in protected environment cages (Techniplast, Buguggiate, Italy) with filter covers that create a barrier at cage level. Water and food were provided ad libitum. Weight changes were recorded weekly. All animal studies were approved by the Danish Animal Experiments Inspectorate and the rules for care and use of animals formulated in the Council of Europe Convention for the Protection of Vertebrate Animals Used for Experimental and Other Scientific Purposes were followed.

\section{Experimental design of feeding studies}

In a long-term feeding study, mice were randomly allocated into five groups each with five mice. For 8 weeks, four of the groups were fed well-defined diets containing either 0 (control), 60 or $240 \mathrm{~g}$ nucleic acid-reduced BP/kg or $240 \mathrm{~g}$ basic BP/kg (Table 1). The fifth group were fed $240 \mathrm{~g}$ nucleic acid-reduced BP/kg for the first 2 weeks only and then fed the control diet for the remaining 6 weeks. The concentrations of macronutrients, vitamins and minerals were adjusted according to the amount of added BP.

In another study, mice were randomly allocated into three groups each with six mice. Two of these groups were fed the control diet and $240 \mathrm{~g}$ basic BP/kg respectively for 4 weeks. The third group was fed for 4 weeks with the control diet but with the addition of BP-culture homogenate to the drinking water $(175 \mathrm{mg}$ protein $/ \mathrm{ml})$; this corresponded to a BP-derived protein intake equal to that of the group fed $240 \mathrm{~g}$ basic BP/ $\mathrm{kg}$ (approximately $0.8 \mathrm{~g}$ protein/mouse per $\mathrm{d}$ ), based on a daily feed and water consumption of $4-5 \mathrm{~g}$ and $4-5 \mathrm{ml}$ respectively. The amount of water consumed was recorded.

From all mice blood was collected weekly from the retro-orbital plexus and diluted in PBS-Triton X-100 (0.01 M-PBS with $1.0 \mathrm{ml}$ Triton X-100/litre, $\mathrm{pH} \mathrm{7.4)}$ and stored at $-20^{\circ} \mathrm{C}$ until analysis. Saliva samples were obtained from all groups with the exception of the group 
Table 1. Composition of experimental diets $(\mathrm{g} / \mathrm{kg})$

\begin{tabular}{lrrr}
\hline & \multicolumn{3}{c}{ Feed } \\
\cline { 2 - 4 } Component & $0 \mathrm{~g} / \mathrm{kg}$ & $60 \mathrm{~g} / \mathrm{kg}$ & $240 \mathrm{~g} / \mathrm{kg}$ \\
\hline BioProtein (approximately 750 protein/kg) & 0 & 60 & 240 \\
Caseinate (approximately 890 protein/kg) & 180 & 130 & 0 \\
Sucrose & 34 & 34 & 32 \\
Yellow dextrin & 34 & 34 & 32 \\
Maize starch & 306 & 304 & 288 \\
Potato starch & 306 & 304 & 288 \\
Mineral mixture & 28 & 28 & 28 \\
Vitamin B mixture & 12 & 12 & 12 \\
Soyabean oil with fat-soluble vitamins & 50 & 45 & 30 \\
Cellulose & 50 & 50 & 50 \\
\hline
\end{tabular}

*Norferm Danmark, Odense, Denmark.

fed only $60 \mathrm{~g}$ basic BP/ $\mathrm{kg}$ by holding a pre-weighed wad of cotton in the mouth of the mouse for $2 \mathrm{~min}$ and then reweighing the cotton wad to calculate the amount obtained. The net weight of captured saliva was approximately $15 \mathrm{mg}$. The saliva was diluted 32-fold by adding PBS-Triton X-100 to the tube containing the cotton wad. After gentle shaking for $5 \mathrm{~min}$, the samples were stored at $-20^{\circ} \mathrm{C}$ until analysis.

\section{Antibody titre determination by ELISA}

BP-specific antibodies in blood and saliva were determined by ELISA. Microtitre plate wells (Maxisorp; Nunc, Roskilde, Denmark) were coated overnight at $4^{\circ} \mathrm{C}$ with $100 \mu \mathrm{l}$ BP extract prepared as described earlier at a concentration of $35 \mu \mathrm{g}$ protein $/ \mathrm{ml}$ carbonate buffer. After washing four times in wash buffer (PBS-Triton X-100 diluted $1: 10), 100 \mu \mathrm{l}$ serially diluted sample was added to each well and the plate was incubated for $1 \mathrm{~h}$ at $37^{\circ} \mathrm{C}$. After washing again, the plate was incubated for $1 \mathrm{~h}$ further with $100 \mu \mathrm{l}$ secondary antibody per well. For total immunoglobulin (Ig) determination, a horseradish (Amoracia rusticana) peroxidase-conjugated rabbit anti-mouse Ig antibody (Dako, Glostrup, Denmark) was used. For determination of BP-specific $\operatorname{IgM}, \operatorname{IgG}_{1}, \operatorname{IgG}_{2 \mathrm{a}}$ and $\operatorname{IgA}$, rabbit anti-mouse antibody specific to the respective antibody isotypes (Zymed, San Francisco, CA, USA) were used and an additional step, involving $1 \mathrm{~h}$ incubation with horseradish peroxidase-conjugated swine anti-rabbit Ig antibody (Dako) was carried out. The plate was developed by adding $100 \mu \mathrm{l}$ substrate solution containing $3,3^{\prime}, 5,5^{\prime}$-tetramethylbenzidin per well and incubated for $10 \mathrm{~min}$. The reaction was stopped by adding $100 \mu \mathrm{l} 2 \mathrm{M}$-phosphoric acid per well and the absorbance at $450 \mathrm{~nm}$ with $630 \mathrm{~nm}$ as reference was measured. A positive control consisting of pooled blood collected at day 21 from mice immunized on days 0 and 14 with BP extract in Freund's incomplete adjuvant was included in all ELISA runs. All samples were run in duplicate. Results were determined as titres, defined as the sample dilution giving an absorbance of $0 \cdot 2$.

\section{In vitro spleen cell proliferation assay}

Single cell suspensions were prepared aseptically from each mouse spleen by mechanical means and centrifuged for $10 \mathrm{~min}$ at $300 \mathrm{~g}$. For removal of erythrocytes, the cells were treated with $\mathrm{NH}_{4} \mathrm{Cl}(8.3 \mathrm{~g} / 1,5 \mathrm{~min}$ on ice) and then washed twice in Dulbecco's modified Eagle's medium (BioWhittaker Europe, Verviers, Belgium) supplemented with $100 \mu \mathrm{g}$ penicillin and $100 \mathrm{IU}$ streptomy$\mathrm{cin} / \mathrm{ml}$. Finally, cells were resuspended in serum-free medium (X-vivo 10; BioWhittaker, Walkersville, MD, USA) supplemented with $2 \mathrm{~mm}-\mathrm{L}-$ glutamine, $100 \mu \mathrm{g}$ penicillin/ml and $100 \mathrm{IU}$ streptomycin/ml and cultured as $3 \times 10^{5}$ cells $/ 225 \mu$ l per well in quadruplicate in a ninetysix-well flat-bottomed plate (Nunc) with $50 \mu \mathrm{g}$ BP extract $/ \mathrm{ml}$ prepared as described earlier or PBS as control. After incubation for $3 \mathrm{~d}$ at $37^{\circ} \mathrm{C}$ in $5 \% \mathrm{CO}_{2}$, cells were pulsed for another $20 \mathrm{~h}$ with $\left[{ }^{3} \mathrm{H}\right]$ thymidine $(37.00 \mathrm{kBq} /$ ml; Amersham International, Amersham, Bucks., UK). After harvesting onto glass-fibre filter-mats using a twelvewell cell harvester (Automash 2000; Dynex, Denkendorf, Germany), the cell proliferation was determined by measuring $\left[{ }^{3} \mathrm{H}\right]$ thymidine incorporation by liquid scintillation counting (Tri-Carp; Packard, Meriden, NJ, USA).

\section{SDS-PAGE and immunoblotting}

BP-culture homogenate $(4 \mathrm{mg}$ protein/ml) dissolved 1:2 and boiled for $5 \mathrm{~min}$ in Tris-SDS sample buffer $(0.1 \mathrm{M}$ Tris-base, SDS $(80 \mathrm{~g} / \mathrm{l})$, glycerol $(240 \mathrm{ml} / \mathrm{l})$, Coomassie $(0.25 \mathrm{~g} / \mathrm{l}), \mathrm{pH} 6 \cdot 8)$ containing $40 \mathrm{~mm}$-dithiothreitol was subjected to SDS-PAGE (125 V for $1 \mathrm{~h}$ ) using a $10-20 \%$ gradient tricine gel (Novex; Invitrogen, Groningen, The Netherlands) (Schagger \& vonJagow 1987). SeeBlue (Invitrogen) was used as standard marker.

The SDS-PAGE gel was blotted onto a nitrocellulose membrane $(0.45 \mu \mathrm{m}, 100 \times 80 \mathrm{~mm})$ for $100 \mathrm{~min}$ at $64 \mathrm{~mA}$ using 3-(cyclohexylamino)propanesulfonic acid buffer $(0 \cdot 1 \mathrm{~mol} / \mathrm{l}$ methanol $(100 \mathrm{ml} / \mathrm{l}), \mathrm{pH} 11 \cdot 0)$. The membrane was blocked for unspecific binding by incubating for $15 \mathrm{~min}$ in TBS-T buffer (50 mM-Tris-base, $0.3 \mathrm{M}-\mathrm{NaCl}$, Tween $20(10 \mathrm{~g} / \mathrm{l}), \mathrm{pH} 10 \cdot 3)$. Then the membrane was cut appropriately into strips, which were incubated overnight at room temperature with blood (diluted 1:160 in TBS-T buffer) from mice at day 0 (control for background response) and day 28 of feeding with $240 \mathrm{~g} \mathrm{BP} / \mathrm{kg}$. The strips were washed three times for $10 \mathrm{~min}$ with TBS-T buffer and then incubated for $1 \mathrm{~h}$ with alkaline phosphatase-conjugated rabbit anti-mouse Ig (Dako). The strips were washed 
and developed in the dark with Nitroblue Tetrazolium chloride and 5-bromo-4-chloro-3-indolyl phosphate as colour substrate. The strip with the standard marker was blocked for $15 \mathrm{~min}$ with blocking buffer (Dako), rinsed for $5 \mathrm{~min}$ in incubation buffer (Dako) and then incubated overnight at room temperature with citrate buffer $(50 \mathrm{~mm}, \mathrm{pH} 3.0)$. Then the strip was stained for approximately $30 \mathrm{~min}$ with freshly prepared colloidal $\mathrm{Au}$ sols solution (Moeremans et al. 1985).

\section{Statistic analysis}

Data was analysed using Statistical Analysis Systems statistical software package (version 6.12; SAS Institute, Cary, NC, USA). For the feeding studies involving data collection over time from the same animals, two-way ANOVA with repeated measures on one factor was performed using the 'proc mixed' procedure to determine the effect of group, day and the interaction between group and day. If significant, the analyses were followed by a difference of least squares means test to determine effects of groups at individual times. For analysis of cell proliferation data, a one-tailed unpaired $t$ test with Welch's correction was used, as equal variance could not be assumed in the control and the dosed group. $P \leq 0.05$ was considered significant. To improve visualization and simplicity of graphs, results are presented as mean values subtracted from the mean of the control to correct for background variations, with the standard errors of the difference set as error bars.

\section{Results}

\section{8-Week feeding study}

In order to examine in more detail the immune response found in previous studies (Mølck et al. 2002) to be induced towards ingested BP, an 8-week BP-feeding study in mice was undertaken. Blood and saliva samples (collected weekly) were subjected to ELISA analysis to monitor the course of the systemic and mucosal humoral immune response respectively. No significant difference in weight gain was observed between the control and the BP-fed groups.

Feeding mice a diet containing $240 \mathrm{~g}$ nucleic acidreduced $\mathrm{BP} / \mathrm{kg}$ induced a statistically significant specific systemic antibody response within 1 week of feeding, measured as total BP-specific Ig in blood (Fig. 1(a)). The response increased rapidly during the first 2 weeks and then after an intermediate reduction, reached a steadystate level at about week 5, lasting the remainder of the experimental period. Further analysis of blood samples revealed a modest but significant peak level of BP-specific IgM (titre $1.2($ SE $0 \cdot 2)$ greater than control value, $P \leq 0.023)$ after $1-2$ weeks that afterwards rapidly declined (results not shown), while the BP-specific IgG (measured as $\mathrm{IgG}_{1}$ and $\mathrm{IgG}_{2 \mathrm{a}}$ ) abruptly increased in this period and continued increasing until reaching a steady state level (Fig. 3).

Feeding mice only $60 \mathrm{~g}$ nucleic acid-reduced $\mathrm{BP} / \mathrm{kg}$ also induced a significant but much less profound BP-specific Ig response in blood; this did not reach a statistically significant level until day 14, as compared with day 7 for the group fed $240 \mathrm{~g}$ nucleic acid-reduced $\mathrm{BP} / \mathrm{kg}$ (Fig. 1(a)). Likewise, the response remained significantly below the level of the group fed $240 \mathrm{~g}$ nucleic acid-reduced $\mathrm{BP} / \mathrm{kg}(P \leq 0 \cdot 0001)$ from day 7 onwards.

A significant response of BP-specific IgA was found in both blood and saliva for nucleic acid-reduced BP-fed mice (Fig. 1(b and c)). Looking at the mice fed $240 \mathrm{~g}$
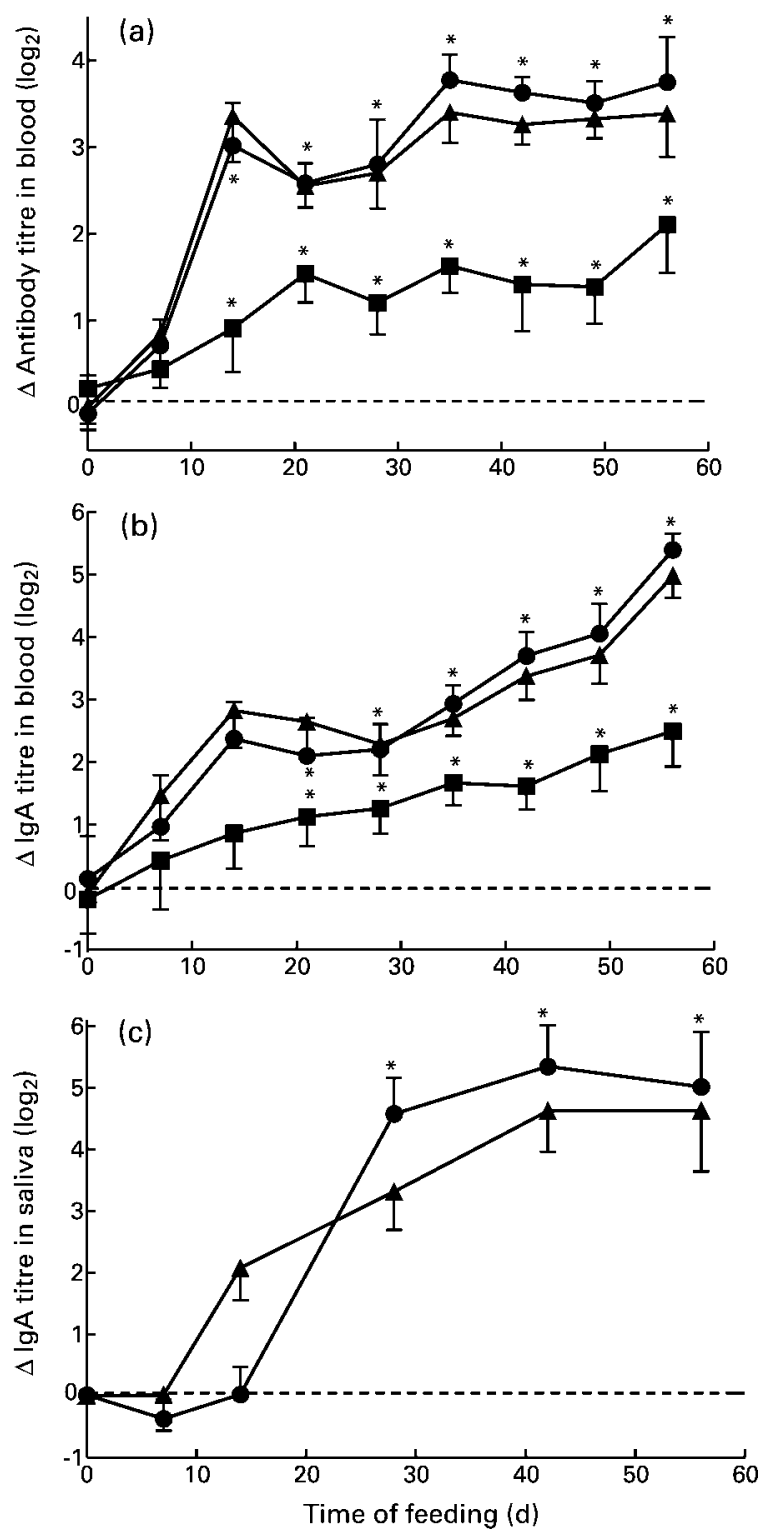

Fig. 1. BioProtein (BP; Norferm Danmark, Odense, Denmark)specific immunoglobulin (Ig) in blood (a) IgA in blood (b) and IgA in saliva (c) monitored by ELISA for mice fed for $56 \mathrm{~d}$ with $60 \mathrm{~g}$ nucleic acid-reduced BP/ $\mathrm{kg}(\boldsymbol{\square}), 240 \mathrm{~g}$ nucleic acid-reduced BP $(\bullet)$ or $240 \mathrm{~g}$ basic BP/ $\mathrm{kg} \mathrm{( \Lambda )} \mathrm{(} n 5$ per group). For details of diets and procedures, see Table 1 and pp. 170-171. Results are presented as mean values with the mean value of a control group subtracted. For all measurements of the control group, mean values were 10.5 (SEM 0.2) for Ig in blood, 6.2 (SEM 0.2) for IgA in blood and 6.1 (SEM $0.3)$ for IgA in saliva, representing the average unspecific background. Standard errors are shown by vertical bars. Mean values were significantly different from those of the control group (two-way ANOVA with repeated measures on one factor): ${ }^{\star} P \leq 0.05$. 
nucleic acid-reduced $\mathrm{BP} / \mathrm{kg}$, the $\operatorname{Ig} \mathrm{A}$ response in blood increased rapidly until day 14 where it stabilized until day 28 and then further increased during the remaining time of assessment. The BP-specific IgA in saliva, however, emerged not until some time after day 14 , when it increased swiftly and then stabilized at about day 28 . Thus, it appears that the increase in anti-BP $\operatorname{IgA}$ response in saliva coincided with the transient stabilization of the blood anti-BP IgA and furthermore, that at the time of saliva anti-BP response stabilization, the anti-BP $\operatorname{IgA}$ in blood started to increase again.

To address whether the nucleic acid reduction processing of BP modifies the effect of BP on the immune system, a comparison of the immune response of mice fed nucleic acid-reduced BP $v$. basic BP was performed. No statistically significant difference appeared between the two BP products for either of the tested antibodies including BP-specific total immunoglobulin and $\operatorname{IgA}$ (Fig. 1) and $\operatorname{IgG}_{1}$ and $\operatorname{IgG}_{2 \mathrm{a}}$ tested in blood only at day 0 and 56 (results not shown).

To assess the immune response towards BP after ingestion of BP has ceased, a group of mice was fed $240 \mathrm{~g}$ nucleic acid-reduced BP/kg for 2 weeks and then fed the control diet for the remaining 6 weeks of the experimental period. For the first 4 weeks, the total BP-specific serum antibody response did not differ statistically from that of the group fed $240 \mathrm{~g}$ nucleic acid-reduced BP/kg continuously (Fig. 2(a)). However, beginning at day 28, i.e. 1 week after feeding nucleic acid-reduced BP was discontinued, the serum antibody response declined steadily as opposed to the group continuously fed nucleic acidreduced $\mathrm{BP}$, showing that the continued exposure sustained the antibody production. Interestingly, when examining the IgG subclass antibodies $\operatorname{IgG}_{1}$ and $\operatorname{IgG}_{2 \mathrm{a}}$ (Fig. 3), the $\operatorname{IgG}_{1}$ response declined considerably subsequent to discontinuing nucleic acid-reduced BP feeding, whereas the $\operatorname{IgG}_{2 \mathrm{a}}$ was completely unaffected and did not differ statistically at any time from the response of the group fed nucleic acid-reduced BP continuously. After ceasing nucleic acid-reduced BP feeding, the BP-specific IgA response in blood declined to an insignificant level by day 28 , while the BP-specific IgA in saliva remained at a substantial level (Fig. 2(b)) showing that the BP-specific IgA production is induced solely at mucosal sites with no manifest systemic IgA response.

\section{BioProtein-specific cellular response}

BP-specific cell activity was measured after feeding BP as the spleen cell proliferative response towards in vitro $\mathrm{BP}$ extract stimulation for mice fed $240 \mathrm{~g}$ nucleic acid-reduced $\mathrm{BP} / \mathrm{kg}$ for $14 \mathrm{~d}$ compared with the control group (Fig. 4). The result showed a statistically significant response $(P=0 \cdot 0012)$, indicating that $\mathrm{T}$ cells have been activated.

\section{Feeding study with BioProtein-culture homogenate}

For the purpose of investigating whether the observed immunogenic potency of BP is influenced by the particulate nature of the product, a study was completed based on feeding mice for 4 weeks with an amount of whole cell-free homogenate of BP culture, equal, regarding protein intake, to a group of mice fed $240 \mathrm{~g}$ basic BP/ $\mathrm{kg}$. A non-BP-fed control group was also included. The intake of BP-derived protein either from BP-culture
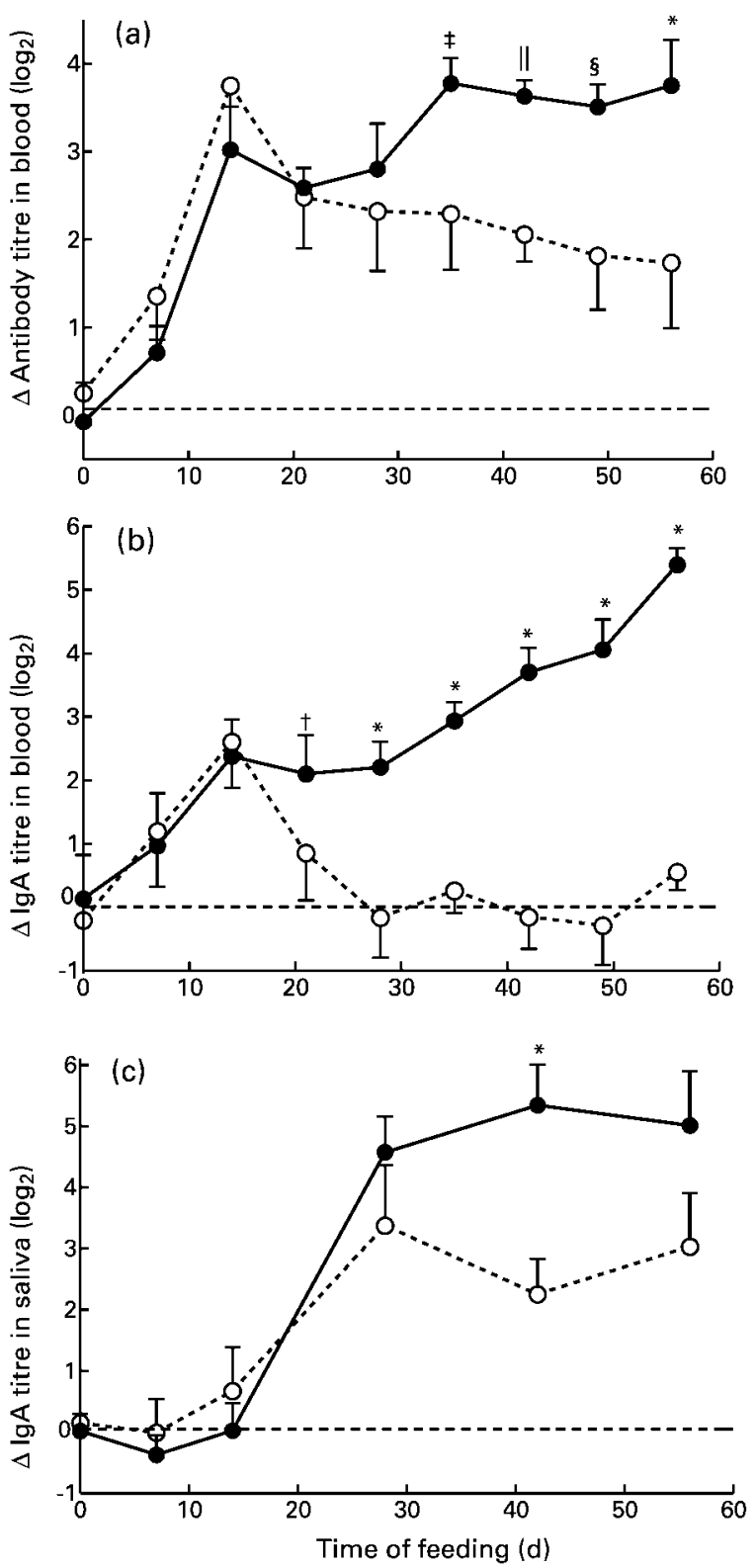

Fig. 2. BioProtein (BP; Norferm Danmark, Odense, Denmark)specific immunoglobulin (Ig) in blood (a) $\lg A$ in blood (b) and $\lg A$ in saliva (c) monitored by ELISA for mice fed $240 \mathrm{~g}$ nucleic acidreduced $\mathrm{BP} / \mathrm{kg}$ on days $1-14$ and then control diet on days $15-56$ (O) or $240 \mathrm{~g}$ nucleic acid-reduced BP/kg on days $1-56(\bullet)$ ( $n 5$ per group). For details of diets and procedures, see Table 1 and pp. 170-171. Results are presented as mean values with the mean value of a control group subtracted. For all measurements of the control group, mean values were 10.5 (SEM 0.2) for Ig in blood, 6.2 (SEM 0.2) for IgA in blood and 6.1 (SEM 0.3) for IgA in saliva, representing the average unspecific background. Standard errors are shown by vertical bars. Mean values were significantly different between the groups shown (two-way ANOVA with repeated measures on one factor): ${ }^{*} P \leq 0.0001, \dagger P=0.022, \ddagger P=0.0029$, $\S P=0.0007, \| P=0.0004$. Other differences were not statistically significant $(P \geq 0.05)$. 

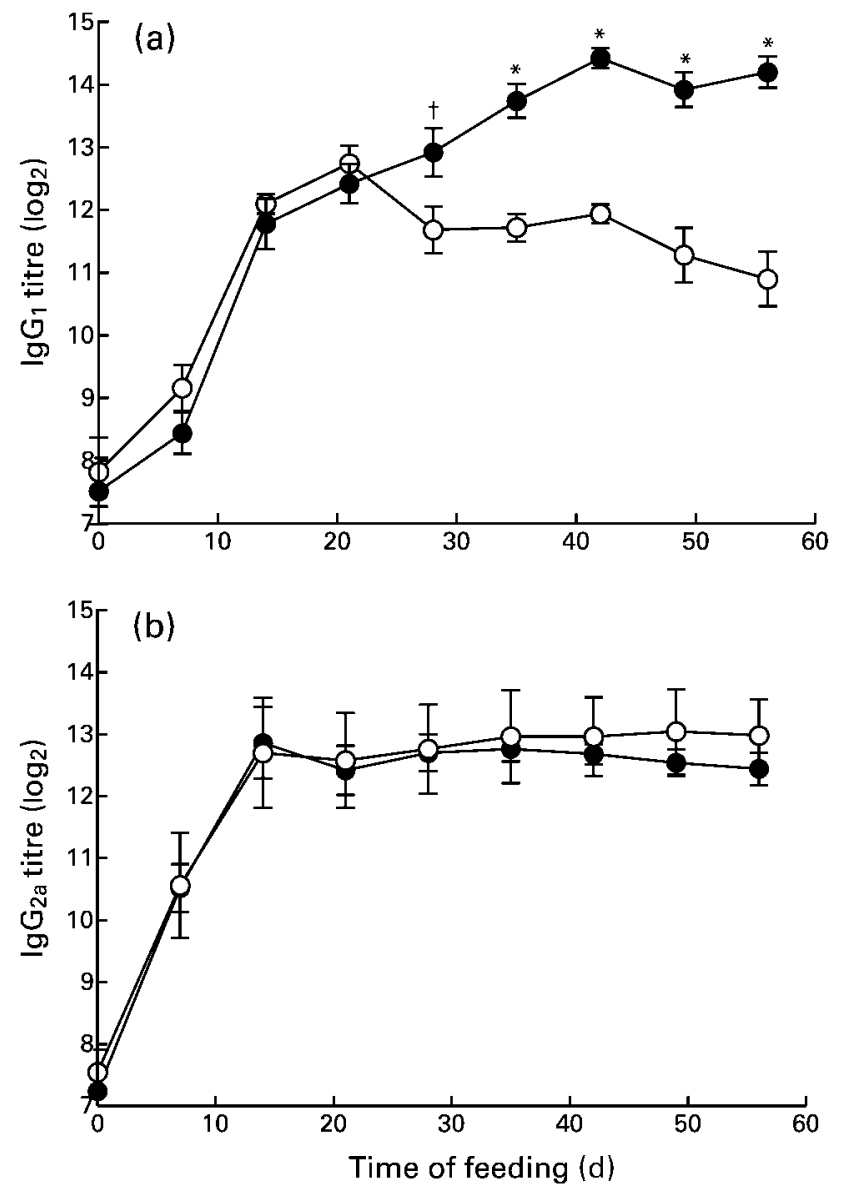

Fig. 3. BioProtein (BP; Norferm Danmark, Odense, Denmark)specific immunoglobulin (Ig) $G_{1}$ (a) and $\lg _{2 a}$ (b) monitored by ELISA in blood from mice fed $240 \mathrm{~g}$ nucleic acid-reduced $\mathrm{BP} / \mathrm{kg}$ on days 1-14 and then control diet on days 15-56 (O) or $240 \mathrm{~g}$ nucleic acid-reduced BP on days 1-56 (๑) ( $n 5$ per group). For details of diets and procedures, see Table 1 and pp. 170-171 Results are presented as mean values with their standard errors shown by vertical bars. Background values of the control-fed animals were not measured. Mean values were significantly different between the groups shown (two-way ANOVA with repeated measures on one factor): ${ }^{*} P \leq 0.0001,+P=0.0138$. Other differences were not statistically significant $(P \geq 0.05)$.

homogenate supplied through the drinking water or via the diet did not vary significantly between the two BP-fed groups at any time during the feeding period.

Interestingly, the BP-culture homogenate-fed mice did not develop a significant BP-specific systemic serum antibody response, as did the mice fed basic BP (Fig. 5(a)). However, though not statistically significant $(P=0 \cdot 21)$, a modest serum BP-specific $\operatorname{IgA}$ response seemed to appear at day 28 (Fig. 5(b)). Surprisingly, the mice fed the BP-culture homogenate developed a BP-specific IgA response in saliva of a magnitude not statistically different from that induced in mice fed basic BP (Fig. 5(c)), clearly showing that the mucosal immunogenicity of BP-culture homogenate is retained in the absence of systemic immunogenicity. In examining whether the immunogenic compounds were removed during the processing of BPculture homogenate explaining the absence of systemic immunogenicity of BP-culture homogenate, the blood

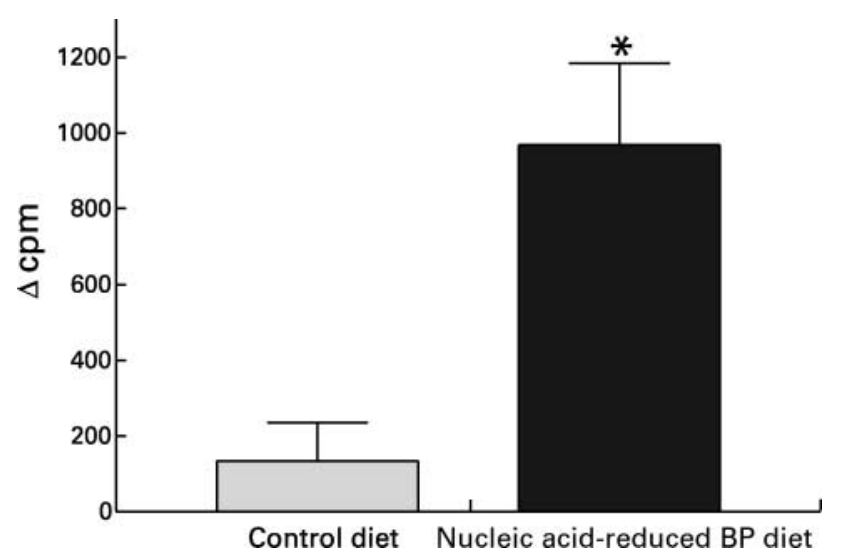

Fig. 4. Proliferation of spleen cells from mice fed $240 \mathrm{~g}$ nucleic acidreduced BioProtein (BP; Norferm Danmark, Odense, Denmark)/kg for $14 \mathrm{~d}$. Spleen cells were stimulated in vitro with either nothing (background) or BP extract ( $50 \mu \mathrm{g}$ protein $/ \mathrm{ml}$ ) for $3 \mathrm{~d}$ before pulsing for $20 \mathrm{~h}$ with $\left[{ }^{3} \mathrm{H}\right]$ thymidine. For details of diets and procedures, see Table 1 and pp. 170-171. Results representing delta counts per $\min (\Delta \mathrm{cpm})$ are shown as mean values with their standard errors shown by vertical bars ( $n 4$ per group). Mean values were significantly different from those of the control group (one-tailed unpaired $t$ test with Welch's correction, as equal variance could not be assumed in the control and the test group): ${ }^{\star} P=0.0012$.

samples were further analysed for BP-culture homogenate-specific antibodies with ELISA. The mice fed BP-culture homogenate still failed to have specific antibodies whereas the BP-fed mice showed a significant response (Fig. 6(a)), demonstrating that the very same antigens are present in $\mathrm{BP}$ as in BP-culture homogenate. This was further substantiated by the appearance of bands in immunoblots of BP-culture homogenate and serum from mice fed basic BP (Fig. 6(b)).

\section{Discussion}

The gut-associated lymphoid tissue is capable of discriminating between harmless antigens coming from the diet or resident microflora and antigens derived from pathogens or toxic agents. The outcome of exposure of foreign antigens to mucosal tissue ranges from induction of non-responsiveness (tolerance), induction of systemic priming to induction of a local mucosal IgA response (Strobel \& Mowat, 1998). Although the regulating mechanisms are far from clear, it is believed that tolerance is the default response to pure soluble antigens, whereas productive immunity is induced only when the antigen is endowed with particular immune activating signals (Strober \& Coffman, 1997). Under healthy conditions, however, human subjects (Husby et al. 1985; Barnes et al. 1988; Ahmed et al. 1997; Rumbo et al. 1998), as well as rodents (Coombs et al. 1983; Wold et al. 1989; Kim et al. 1993), may develop a weak systemic and mucosal antibody response to long-term dietary antigen exposure. Such antibody responses vary a great deal among individuals and typically occur only transiently in young individuals and tend to decline with age, probably due to development of tolerance (Husby et al. 1985; Dannaeus 1993; Ahmed et al. 1997).

The present study showed that mice fed for 8 weeks with $240 \mathrm{~g}$ nucleic acid-reduced $\mathrm{BP} / \mathrm{kg}$ consistently 

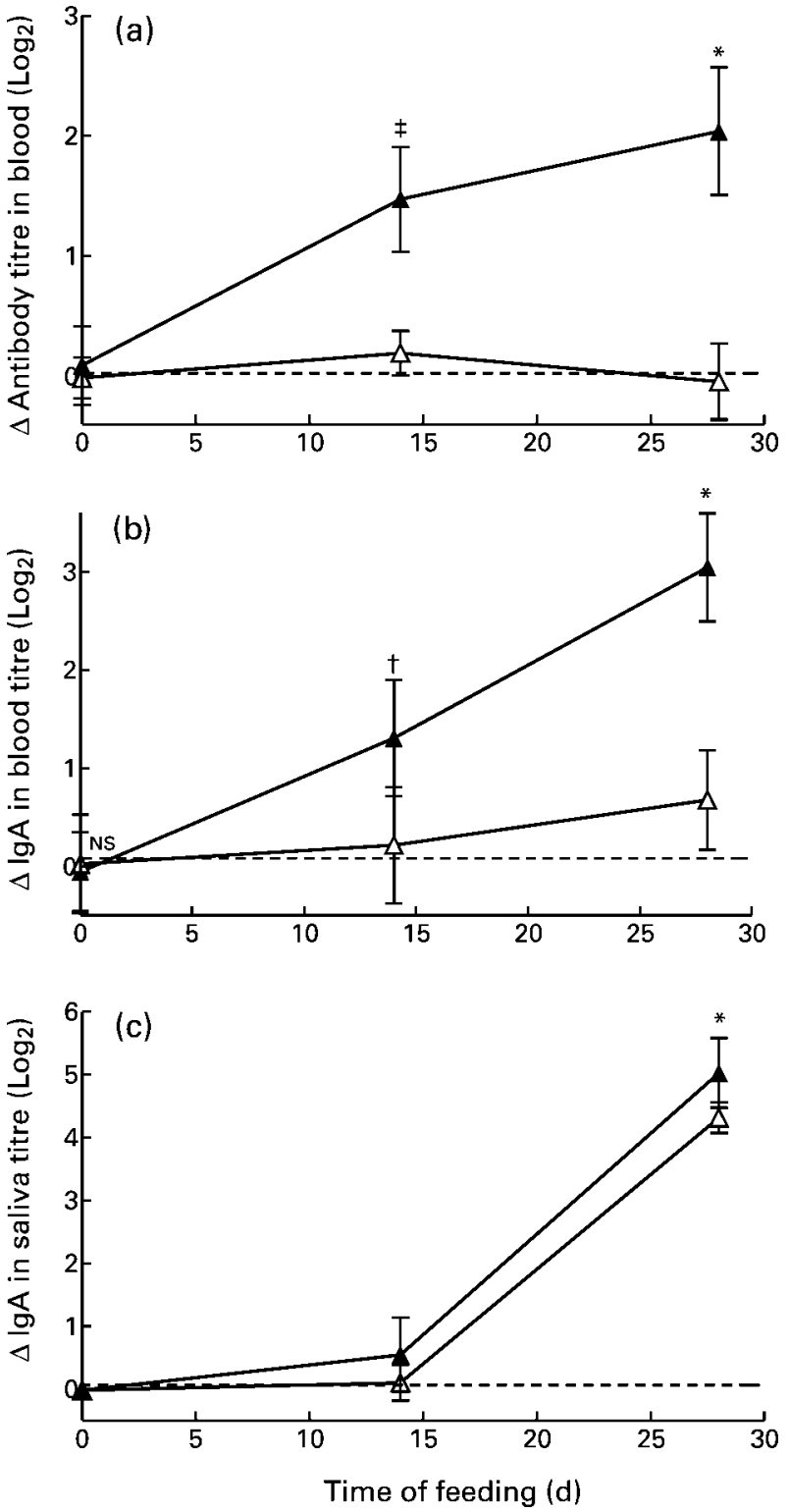

Fig. 5. BioProtein (BP; Norferm Danmark, Odense, Denmark)specific immunoglobulin (Ig) in blood (a) IgA in blood (b) and IgA in saliva (c) monitored by ELISA for mice fed for $28 \mathrm{~d}$ with 240 basic $\mathrm{BP} / \mathrm{kg}(\boldsymbol{\Lambda})$ or BP-culture homogenate $(\triangle)$ with equal BP-derived protein intake ( $n 5$ per group). For details of diets and procedures, see Table 1 and pp. 170-171. Results are presented as mean values with the mean value of a control-fed group subtracted. Standard errors are shown by vertical bars. For all measurements of the control group, mean values were 9.2 (SEM 0.3) for lg in blood, 5.8 (SEM 0.4) for IgA in blood and 5.1 (SEM 0.1 ) for IgA in saliva, representing the average unspecific background. Mean values were significantly different from those of the control group (two-way ANOVA with repeated measures on one factor): ${ }^{\star} P \leq 0.0001,+P=0.029$, $\ddagger P=0.0004$. Other differences were not statistically significant $(P \geq 0.05)$, including between BP-fed groups in (c).

developed a clear and persistent BP-specific immune response characterized by both a systemic (Ig in blood) and a mucosal (IgA in saliva) response (Fig. 1). The immune response was moreover found to be T-cell dependent, as specific splenocyte proliferation took place upon in vitro stimulation with BP. Quantitative assessment of the response magnitude could not be made on the basis of the present study due to the relative form of the results obtained by ELISA. However, the response patterns were very clear and remarkably consistent among the mice, with no animals not responding to ingested $\mathrm{BP}$, indicating an enhanced oral immunogenicity of BP compared with ordinary food antigens. The course of the systemic antibody response resembled that of a typical antibody response generated against immunogens administered parenterally, featuring an initial rapid IgM production succeeded by a much stronger IgG response (Goding, 1996). The serum IgA level decreased readily while saliva $\operatorname{IgA}$ persisted after discontinuing BP feeding, which indicates that the $\operatorname{IgA}$ response detected in serum originated solely from mucosally triggered $\mathrm{B}$ cells occurring transiently in blood, since it is known that $\operatorname{IgA}^{+} \mathrm{B}$ cells triggered in the gut mucosa recirculate through lymph and blood before homing to mucosal effector sites (Macpherson et al. 2001). This could also explain the temporary discontinuance of the increase in serum $\operatorname{IgA}$ at the time where the saliva $\operatorname{IgA}$ response started to develop (about day 14) as $\mathrm{IgA}^{+} \mathrm{B}$ cells may begin homing to mucosal sites by this time.

The processing of SCP to reduce the nucleic acid content is one factor conceivably influencing the constitution of SCP: it has in fact been suspected to be involved in increased oral immunogenicity of SCP products, as clinical tolerance trials in human subjects have indicated a higher potential of the nucleic acid-reduced SCP products to induce allergic reactions than the unaltered products (Scrimshaw \& Murray, 1995). In the present study, mice ingesting $240 \mathrm{~g}$ basic $\mathrm{BP} / \mathrm{kg}$ developed a specific immune response not statistically significantly different at any time from that developed against nucleic acid-reduced $\mathrm{BP}$, suggesting that the nucleic acid-reduction processing of BP had no effect on its oral immunogenicity. Potential difference in the capacities of basic BP and nucleic acidreduced $\mathrm{BP}$ to induce BP-specific IgE was not specifically addressed in the present study. However, when considering the production of the $\operatorname{IgG}$ subclasses $\operatorname{IgG}_{1}$ and $\operatorname{IgG}_{2 \mathrm{a}}$ (measured on day 56, results not shown), no statistical difference occurred between basic BP and nucleic acidreduced $\mathrm{BP}$. $\mathrm{IgG}_{1}$ and $\mathrm{IgE}$ production is supported by T-helper (Th) 2 cells functioning in humoral immunity against exogenous antigens including allergy, whereas $\mathrm{IgG}_{2 \mathrm{a}}$ production is supported by Th1 functioning in cellmediated immunity (Fujihashi et al. 1997). Thus, eliciting identical $\mathrm{IgG}_{1}$ and $\mathrm{IgG}_{2 \mathrm{a}}$ responses suggests that no difference exists in the oral immunogenicity of nucleic acid-reduced $\mathrm{BP} v$. basic $\mathrm{BP}$ with respect to the type of response (Th1 and 2) evoked by the two products.

Prolonged exposure of BP to the gut-associated lymphoid tissue owing to heavy accumulation in macrophages in the mesenteric lymph nodes, as observed in the study by Mølck et al. (2002), may represent another factor potentially involved in the strong antibody response induced towards ingested BP. Moreover, prolonged exposure may differentially affect the response pattern favouring a Th1 cell response, as the $\mathrm{IgG}_{2 \mathrm{a}}$ response is selectively sustained in contrast to the abating $\mathrm{IgG}_{1}$ response subsequent to termination of BP feeding. The half-life of circulating $\mathrm{IgG}_{1}$ 


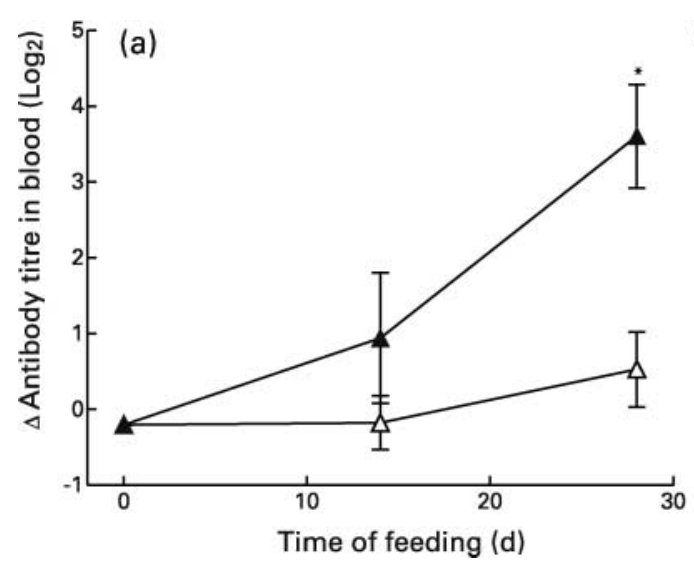

(b)

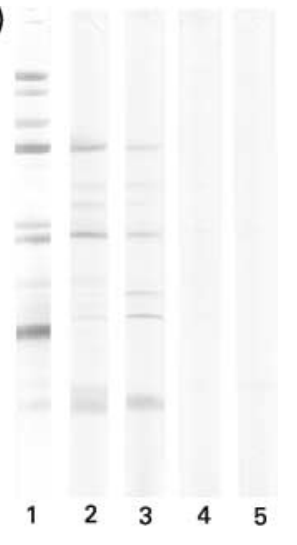

Fig. 6. (a) BioProtein (BP; Norferm Danmark, Odense, Denmark)-culture homogenate-specific immunoglobulin in blood from mice fed for $28 \mathrm{~d}$ with $240 \mathrm{~g}$ basic BP/kg $(\mathbf{\Lambda})$ or BP-culture homogenate $(\triangle)$ ( $n 5$ per group). For details of diets and procedures, see Table 1 and pp. $170-171$. Values are means with the mean value of a control-fed group subtracted. Standard errors are shown by vertical bars. For all measurements of the control group, mean value was 7.9 (SEM 0.3), representing the average unspecific background. Mean values were significantly different from those of the control group (two-way ANOVA with repeated measures on one factor): ${ }^{*} P \leq 0.0001$. Other differences were not statistically significant $(P \geq 0 \cdot 05)$. (b) Immunoblots of BP-culture homogenate with blood from mice fed $240 \mathrm{~g}$ basic BP/kg for $28 \mathrm{~d}$ (lanes $2-3)$ or $0 \mathrm{~d}$ (control; lanes 4-5). Lane 1 is Au-stained blot of SeeBlue (Invitrogen, Groningen, The Netherlands) standard.

and $\mathrm{IgG}_{2 \mathrm{a}}$ is the same (Kerr \& Loomes 1994), suggesting that the factors supporting the Th2 response may be more efficiently cleared from immune exposure than the Th1-driving factors.

The particulate nature of an antigen is yet another factor that greatly enhances oral immunogenicity (O'Hagan et al. 1989; Ermak \& Giannasca 1998). Interestingly, the studies employing basic BP in comparison with BP-culture homogenate clearly revealed that the whole-cell, and thus highly particulate, appearance of BP induced both a local response and a systemic immune response, whilst the BP-culture homogenate, representing identical antigens as in basic BP but in a non whole-cell context, induced only a mucosal response. This demonstrates that factors apart from the antigens per se such as the particulate nature are responsible for the systemic immunogenicity of BP.

The lymphoid aggregates termed Peyer's patches form important inductive sites of the gut-associated lymphoid tissue for initiation of a mucosal IgA response (Brandtzaeg, 1998). Peyer's patches are specialized for sampling particulate materials (macromolecules, viruses and bacteria), whereas soluble antigens are more poorly sampled. Particulate antigens sampled by Peyer's patches have been found to be selectively translocated to the mesenteric lymph nodes and further to systemic lymphoid tissue such as the spleen according to their size (Jenkins et al. 1994; Nakase et al. 2001). Particles of approximately $4 \mu \mathrm{m}$ are efficiently transported to the spleen, whereas both smaller and larger tend to be retained in the Peyer's patches. Moreover, the dissemination of the particulate antigen in the body seems to be a key factor in regulating the induction of systemic and mucosal immune responses (Tabata et al. 1996; Matsunaga et al. 2000). Tabata et al. (1996) found that when particulate antigen is translocated to the spleen, a systemic IgG immune response will take place, whereas when retained in Peyer's patches only a mucosal IgA response will be initiated. These facts could explain the distinct responses induced towards basic BP and
BP-culture homogenate. As basic BP consists of bacteria and bacterial fragments having a particle size range optimal for being partly systemically translocated and partly retained in Peyer's patches, both a systemic and a mucosal immune response is efficiently induced. Though being free of whole bacterial cells hindering a systemic response, BPculture homogenate still contains cell fragments that might be efficiently retained in Peyer's patches and thus a mucosal IgA response is generated. These findings are further supported by the findings in the study by Mølck et al. (2002) showing that nucleic acid-reduced BP appeared to be absorbed from the intestine and transported to the mesenteric lymph nodes, and furthermore seemed likely to undergo a more general dissemination as the liver was also affected. In accordance with this, studies by Dahlgren et al. (1991) clearly show that only when genetically incorporated into gram-negative bacteria, ovalbumin become orally immunogenic, whereas soluble ovalbumin co-administered with the very same bacteria induces no response. Likewise, studies by Wold et al. (1989) show that bacterial antigens exhibit greater oral immunogenicity than dietary antigens.

Despite the fact that the particulate nature of antigens seems to play a very important role in the oral immunogenicity, no such strong immune response occurs to ingested dairy lactic acid bacteria or to the residing gut flora, suggesting that other factors are also involved. Moreover, IgA specific to common dietary antigens is normally not present in saliva in detectable amounts, as was the case for BP-culture homogenate and for basic BP and nucleic acid-reduced BP. Certain microbial products such as lipopolysaccharide are recognised through pattern recognition receptors on antigen presenting cells and mediate an activating signal (Medzhitov \& Janeway 2000). The main organism in the BP culture, Methylococcus capsulatus (Bath), contains lipopolysaccharide as an integral part of the cell membrane (Fjellbirkeland et al. 1997) and thus, at first sight, represents an obvious candidate for an adjuvant component in BP. However, studies have proved the 
complexity of lipopolysaccharide as a mucosal adjuvant as when lipopolysaccharide is co-administered orally with certain antigens it has been found to enhance oral tolerance (Khoury et al. 1990). Moreover, lipopolysaccharide is inherently abundant in the mucosal lumen of the intestine (Haman et al. 1998). Interestingly, recent studies have shown a diversity of the effect of lipopolysaccharide derived from different bacterial species on their antigen presenting cells stimulation, which could explain a specific property in force for the lipopolysaccharide of $M$. capsulatus (Pulendran et al. 2001).

The presence of oral tolerance, as traditionally detected by feeding the antigen and observing for a reduced immune response to a subsequent immunization compared with a non-fed control group, was not specifically addressed in the present study. Studies on this subject are ongoing in our laboratory. Moreover, exhibiting oral immunogenicity, BP holds a potential of being a mucosal adjuvant affecting the immune response towards co-present antigens. Studies on this topic are also ongoing in our laboratory.

In conclusion, BP possesses an oral immunogenicity as both a systemic and mucosal BP-specific antibody response is induced upon ingestion. No differences were found between basic BP and nucleic acid-reduced BP in this matter. The particulate nature of $\mathrm{BP}$ played a crucial role for the initiation of the systemic antibody response, which was avoided by processing the BP culture to a product free of whole bacterial cells. A significant mucosal $\operatorname{IgA}$ response still occurred.

For future applications of SCP such as BP for animal and human consumption, the present study clearly showed that detailed immunological investigations are needed as an important part of the general safety assessment and to identify and characterize the causative factors in attempt to develop safe products. Failure to recognize the importance of appropriate processing, such as the elimination of a particulate constitution shown in the present study, could lead to unnecessary rejection of SCP products as a dietary protein source.

\section{Acknowledgements}

The authors thank animal assistant Lillian Vile and laboratory technicians Anni Mehlsen and Lisbeth B. Larsen for valuable assistance during the experimental work. Thanks are also due to Dr Anne-Marie Mølck and Dr Morten Poulsen, both from The Danish Veterinary and Food Administration, Denmark, for assisting in the statistical analysis of the data, and to Diane Burgess for assisting in the preparation of the manuscript. The study was supported by Centre of Advanced Food Studies, Denmark, and Biotechnology in Food Research Programme, Ministry of Food, Agriculture and Fisheries, Denmark.

\section{References}

Ahmed T, Sumazaki R, Nagai Y, Shibasaki M \& Takita H (1997) Immune response to food antigens: Kinetics of food-specific antibodies in the normal population. Acta Paediatr Jpn 39, $322-328$.
Anupama \& Ravindra P (2000) Value-added food: Single cell protein. Biotechnol Adv 18, 459-479.

Barkholt V \& Jensen AL (1989) Amino-acid analysis - determination of cystein plus half-cystein in proteins after hydrochloric-acid hydrolysis with a disulfide compound as additive. Anal Biochem 177, 318-322.

Barnes RMR, Johnson PM, Harvey MM, Blears J \& Finn R (1988) Human-serum antibodies reactive with dietary proteins IgG subclass distribution. Int Arch Allergy Appl Immunol 87, 184-188.

Brandtzaeg P (1998) Development and basic mechanisms of human gut immunity. Nutr Rev 56, S5-S18.

Coombs RRA, Kieffer M, Fraser DR \& Frazier PJ (1983) Naturally developing antibodies to wheat gliadin fractions and to other cereal antigens in rabbits, rats and guinea-pigs on normal laboratory diets. Int Arch Allergy Appl Immunol 70, 200-204.

Dahlgren UIH, Wold AE, Hanson LA \& Midtvedt T (1991) Expression of a dietary-protein in Echerichia coli renders it strongly antigenic to gut lymphoid-tissue. Immunology 73, 394-397.

Dannaeus A (1993) Age-related antibody response to food antigens. Pediatr Allergy Immunol 4, Suppl. 3, 21-24.

Ermak TH \& Giannasca PJ (1998) Microparticle targeting to M cells. Adv Drug Deliv Rev 34, 261-283.

Fjellbirkeland A, Kleivdal H, Joergensen C, Thestrup H \& Jensen HB (1997) Outer membrane proteins of Methylococcus capsulatus (Bath). Arch Microbiol 168, 128-135.

Fujihashi K, Kweon MN, Kiyono H, VanCott JL, vanGinkel FW, Yamamoto M \& McGhee JR (1997) A T cell/B cell epithelial cell internet for mucosal inflammation and immunity. Springer Semin Immunopathol 18, 477-494.

Goding JW (1996) The Antibody Response, 3rd ed. London: Academic Press.

Haman L, El-Samalouti V, Ulmer AJ, Flad H-D \& Rietschel ET (1998) Components of gut bacteria as immunomodulators. Int J Microbiol 41, 141-154.

Husby S, Oxelius VA, Teisner B, Jensenius JC \& Svehag SE (1985) Humoral immunity to dietary antigens in healthy adults - occurrence, isotype and $\mathrm{IgG}$ subclass distribution of serum antibodies to protein antigens. Int Arch Allergy Appl Immunol 77, 416-422.

Jenkins PG, Howard KA, Blackhall NW, Thomas NW, Davis SS \& O'Hagan DT (1994) Microparticulate absorption from the rat intestine. J Control Release 29, 339-350.

Kerr MA \& Loomes LM (1994) Properties of immunoglobulins. In Immunochemistry Labfax, pp. 23-42 [MA Kerr and R Thorpe, editors]. Oxford: Bios Scientific Publishers.

Khoury SJ, Lider O, Alsabbagh A \& Weiner HL (1990) Suppression of experimental autoimmune encephalomyelitis by oral administration of myelin basic-protein. 3. Synergistic effect of lipopolysaccharide. Cell Immunol 131, 302-310.

Kim SM, Enomoto A, Hachimura S, Yamauchi K \& Kaminogawa S (1993) Serum antibody-response elicited by a casein diet is directed to only limited determinants of alphas1-casein. Int Arch Allergy Immunol 101, 260-265.

Kuhad RC, Singh A, Tripathi KK, Saxena RK \& Eriksson KEL (1997) Microorganisms as an alternative source of protein. Nutr Rev 55, 65-75.

Larsen J \& Joergensen L (1996) Reduction of RNA and DNA in Methylococcus capsulatus by endogenous nucleases. Appl Microbiol Biotechnol 45, 137-140.

Macpherson AJ, Hunziker L, McCoy K \& Lamarre A (2001) $\operatorname{IgA}$ responses in the intestinal mucosa against pathogenic and non-pathogenic microorganisms. Microbes Infect 3, 1021-1035.

Matsunaga Y, Wakatsuki Y, Tabata Y, Kawasaki H, Usui T, Yoshida M, Itoh T, Habu S \& Kita T (2000) Oral immunization 
with size-purified microsphere beads as a vehicle selectively induces systemic tolerance and sensitization. Vaccine 19, $579-588$

Medzhitov R \& Janeway C (2000) Innate immune recognition: mechanisms and pathways. Immunol Rev 173, 89-97.

Moeremans M, Daneels G \& Demey J (1985) Sensitive colloidal metal (gold or silver) staining of protein blots on nitrocellulose membranes. Anal Biochem 145, 315-321.

Mølck A-M, Poulsen M, Christensen HR, Lauridsen TS \& Madsen C (2002) Immunotoxicity of nucleic acid reduced BioProtein - a bacterial derived single cell protein - in Wistar rats. Toxicology 174, 183-200.

Nakase H, Okazaki K, Tabata Y, et al. (2001) Rectal immunization with antigen-containing microspheres induces stronger Th2 responses than oral immunization: a new method for vaccination. Vaccine 20, 377-384.

O'Hagan DT, Palin K, Davis SS, Artursson P \& Sjoholm I (1989) Microparticles as potentially orally active immunological adjuvants. Vaccine 7, 421-424.

Pulendran B, Kumar P, Cutler CW, Mohamadzadeh M, Van Dyke T \& Banchereau J (2001) Lipopolysaccharides from distinct pathogens induce different classes of immune responses in vivo. J Immunol 167, 5067-5076.

Rumbo M, Chirdo FG, Anon MC \& Fossati CA (1998) Detection and characterization of antibodies specific to food antigens (gliadin, ovalbumin and beta-lactoglobulin) in human serum, saliva, colostrum and milk. Clin Exp Immunol 112, 453-458.

Schagger H \& vonJagow G (1987) Tricine sodium dodecylsulfate polyacrylamide-gel electrophoresis for the separation of proteins in the range from 1-KDa to 100-KDa. Anal Biochem 166, 368-379.

Scrimshaw NS \& Murray EB (1995) Nutritional value and safety of single cell protein. In Enzymes, Biomass and Feed, pp. 221-237 [G Reed and TW Nagodawithana, editors]. Weinham: VCH.

Strobel S \& Mowat AM (1998) Immune responses to dietary antigens: oral tolerance. Immunol Today 19, 173-181.

Strober W \& Coffman RL (1997) Tolerance and immunity in the mucosal immune system - Introduction. Res Immunol 148, 489-490.

Tabata Y, Inoue Y \& Ikada Y (1996) Size effect on systemic and mucosal immune responses induced by oral administration of biodegradable microspheres. Vaccine 14, 1677-1685.

Whittenbury R \& Krieg NR (1984) Methylococcaceae. In Bergey's Manual of Systemic Bacteriology, pp. 256-261 [NR Krieg and JG Holt, editors]. Baltimore, MD: Williams and Wilkins.

Wold AE, Dahlgren UIH, Hanson LA, Mattsbybaltzer I \& Midvetdt T (1989) Difference between bacterial and food antigens in mucosal immunogenicity. Infect Immun 57, 2666-2673. 